\title{
Characterization of Striga-Resistant Yellow-Orange Maize Hybrids for Bioactive, Carbohydrate, and Pasting Properties
}

\author{
Abdulazeez Olamilekan Elemosho ${ }^{1,2}$, Emmanuel Anyachukwu Irondi ${ }^{1}$, \\ Emmanuel Oladeji Alamu ${ }^{2 *}$, Emmanuel Oladipipo Ajani ${ }^{1}$, Busie Maziya-Dixon ${ }^{2}$ and \\ Abebe Menkir ${ }^{3}$
}

${ }^{1}$ Department of Medical Biochemistry and Pharmacology, Kwara State University, Ilorin, Nigeria, ${ }^{2}$ Food and Nutrition Sciences Laboratory, International Institute of Tropical Agriculture (IITA), Ibadan, Nigeria, ${ }^{3}$ Maize Breeding Unit, International Institute of Tropical Agriculture (IITA), Ibadan, Nigeria

Understanding the bioactive constituents and physicochemical components in cereals can provide insights into their potential health benefits and food applications. This study evaluated some bioactive constituents, carbohydrate profiles and pasting properties of 16 Striga-resistant hybrids, with yellow-orange kernel color and semi-flint to flint kernel texture, grown in two replications at two field locations in Nigeria. Carotenoids were quantified using HPLC, while other analyses were carried out using standard laboratory methods. The ranges of major carotenoids $(\mu \mathrm{g} / \mathrm{g})$ across the two locations varied from 2.6 to 9.6 for lutein, from 2.1 to 9.7 for zeaxanthin, from 0.8 to 2.9 for $\beta$-cryptoxanthin, from 1.4 to 4.1 for $\beta$-carotene; with total xanthophylls and provitamin A carotenoids (pVAC) ranging from 5.4 to 17.1 and 1.4 to $4.1 \mu \mathrm{g} / \mathrm{g}$, respectively. Tannins content ranged from 2.1 to $7.3 \mathrm{mg} / \mathrm{g}$, while phytate ranged from 0.4 to $7.1 \%$. Starch, free sugar, amylose and amylopectin ranged from 40.1 to $88.9 \%, 1.09$ to $6.5 \%, 15.0$ to $34.1 \%$, and 65.9 to $85.0 \%$, respectively. Peak and final viscosities ranged from 57.8 to 114.9 and 120.3 to 261.6 Rapid Visco Units (RVU), respectively. Total xanthophylls, $\beta$-carotene, tannins, phytate, sugar, amylose and amylopectin levels, as well as peak and final viscosities, varied significantly $(p<0.05)$ across the hybrids. Amylose was significantly correlated $p$ $<0.05)$ with total xanthophylls, $\beta$-carotene, pVAC, phytate and pasting temperature $(r=$ $0.3,0.3,0.4,0.3,0.3$, respectively), but starch significantly correlated with tannins $(r=$ 0.3). Hence, the Striga-resistant yellow-orange maize hybrids have a good combination of bioactive constituents, carbohydrate profile and pasting properties, which are partly influenced by hybrid.

Keywords: Striga-resistant maize, bioactive constituents, carbohydrate profile, pasting properties, carotenoids

\section{INTRODUCTION}

Maize (Zea mays L.) is an important annual cereal crop that is primarily grown for its grains for human consumption (Kumar and Jhariya, 2013). It is the third most important cereal after wheat and rice (Yousaf et al., 2020). In sub-Saharan Africa, maize plays a significant role in reducing poverty and improving the food security status of low-income families (Hu et al., 2008). It also 
serves as a valuable ingredient to the food industry. In developed countries, it is grown for profit-making from feed, fuel and other raw materials for industrial products (Hu et al., 2008). Because of its importance, genetic improvement of maize has played a vital role in the development of genotypes with high technological, nutraceutical and nutritional values (Zilic et al., 2011).

Yellow-orange maize (provitamin A biofortified maize) has received increased attention from a nutraceutical perspective because it contains several bioactive phytochemicals such as carotenoids, phenolic compounds ( $\mathrm{Hu}$ and $\mathrm{Xu}, 2011$; Zilić et al., 2012), tocopherols (Ibrahim and Juvik, 2009), and phytic acid (de la Parra et al., 2007). Although these compounds are considered non-nutritive, the interest in their antioxidant and other bioactive properties has increased due to their potential health benefits. Orange maize genotypes rich in provitamin A carotenoids ( $\beta$-carotene, $\beta$-cryptoxanthin and $\alpha$-carotenes) serve as an essential dietary intervention for alleviating vitamin A deficiency, particularly in developing countries (Menkir et al., 2008). In addition to their vitamin A activity, carotenoids are prominent for their antioxidant activities and protective effects against chronic diseases such as cardiovascular diseases (Gammone et al., 2017) and cancer (Agarwal and Rao, 2000). Seifried et al. (2007) reported that the antioxidant activity of carotenoids is the primary mechanism of their health benefits. In addition to the already mentioned health benefits, recent studies have indicated that consumption of diets rich in carotenoids may help protect against the development of type 2 diabetes (T2D) (Sugiura et al., 2015).

Tannins (water-soluble polyphenols) have been reported to be available in maize (Chung et al., 1998). Although tannins form complexes with proteins, reducing their digestibility and utilization (Polycarp et al., 2012), they possess anti-carcinogenic and antimutagenic potentials due to their antioxidative property (Chung et al., 1998). Similarly, phytate has been reported to selectively exhibit anticancer activity on only malignant cells, without affecting normal cells and tissues (Vucenik and Shamsuddin, 2003). It may also inhibit the development of renal stone (Dost and Tokul, 2006). However, it has a strong ability to chelate divalent metal ions, especially iron, zinc and calcium, thereby reducing their bioavailability in the gastrointestinal tract (Bohn et al., 2008).

Yellow-orange maize varieties also have an impressive nutritional profile. They contain a high content of carbohydrates, with starch being the most abundant component, and appreciable levels of protein and other nutrients. The starch in yellow-orange maize consists of about 75\% amylopectin and 25\% amylose (Karim et al., 2000), and this has an impact on its pasting properties (Horstmann et al., 2016). Cissé et al. (2013) earlier observed considerable variability in the pasting properties of starches from different quality protein maize.

Striga-resistant yellow-orange maize hybrids are the product of introducing a single nuclear gene that confers resistance to imidazolinone herbicides, including metsulfuron methyl, into inbred lines with known field resistance to Striga hermonthica (Menkir, 2014). The performance of these genotypes can vary from one environment to another. So, genotypes that are superior in one environment may not be superior in other environments.
This can result in variation in their nutritional and bioactive components. Striga-resistant yellow-orange maize hybrids can mature early under low soil nitrogen and drought condition (Benjamin et al., 2019). Thus, breeding Striga-resistant hybrids will increase maize production and lead to improved incomes and livelihoods of farmers as well as enhance the sustainability of the seed companies (Menkir, 2006; Menkir et al., 2012).

The potential health benefits and food applications of cereals are attributed to their bioactive and physicochemical constituents, and these may vary depending on some factors. Previous studies have reported on the effects of genotype and environment on the bioactive compounds in biofortified yelloworange maize (Muzhingi et al., 2016; Alamu et al., 2018). However, there is a paucity of scientific information on the bioactive constituents and physicochemical attributes of Strigaresistant yellow-orange maize hybrids, and the possible influence of hybrid (genotype) and location on them. Therefore, this study was conducted to characterize the bioactive, carbohydrate and pasting properties of Striga-resistant yellow-orange maize hybrids grown at two field locations (Zaria and Saminaka) in Nigeria, to provide insight into their potential health benefits and food applications.

\section{MATERIALS AND METHODS}

\section{Collection and Preparation of Samples}

Sixteen Striga-resistant yellow-orange maize hybrids grown in two replications at Zaria $\left(7^{\circ} 45^{\prime} \mathrm{E}, 11^{\circ} 8^{\prime} \mathrm{N}\right.$; altitude $622 \mathrm{~m}$; annual rainfall $1,076 \mathrm{~mm}$, average temperatures $13.9-35.5^{\circ} \mathrm{C}$, and soil type Ferric Luvisols) and Saminaka $\left(8^{\circ} 39^{\prime} \mathrm{E}, 10^{\circ} 34^{\prime} \mathrm{N}\right.$; altitude $760 \mathrm{~m}$; annual rainfall $1,149 \mathrm{~mm}$, average temperatures $18.1-$ $37.3^{\circ} \mathrm{C}$, and soil type Dystric Nitosols) were collected from the Maize Improvement Programme of the International Institute of Tropical Agriculture (IITA), Ibadan, Nigeria. The samples, with a constant moisture level of $10 \%$, were milled to $0.50 \mathrm{~mm}$ sieve size with Perten Laboratory Hammer Mill $(3,102)$ and packed in sample bags for further laboratory analysis. Samples for carotenoids analysis were kept in $-80^{\circ} \mathrm{C}$ freezer, while those for other analyses were kept in $4^{\circ} \mathrm{C}$ refrigerator.

\section{Carotenoids Analysis Using HPLC}

The method of Howe and Tanumihardjo (2006) was employed to determine the composition and content of carotenoids in the samples. Carotenoids were extracted from maize samples by ethanol precipitation in which $0.6 \mathrm{~g}$ of sample was mixed with ethanol $(6 \mathrm{~mL})$ containing $0.1 \%$ butylated hydroxyl toluene, and placed in a water bath at $85^{\circ} \mathrm{C}$ for $5 \mathrm{~min}$. This was followed by saponification of the interfering oil in the mixture with potassium hydroxide $(80 \% \mathrm{w} / \mathrm{v})$ at $85^{\circ} \mathrm{C}$ in a water bath for $5 \mathrm{~min}$. The mixture was vortexed and returned to the water bath for another $5 \mathrm{~min}$, after which it was immediately transferred into an ice bath, where $3 \mathrm{~mL}$ of cold deionized water was added to it. Carotenoids were separated three consecutive times with $3 \mathrm{~mL}$ of hexane by vortexing, centrifuging at $112 \mathrm{~g}$-force for $10 \mathrm{~s}$ and pipetting the upper phase into a $50 \mathrm{~mL}$ concentrator tube. The combined hexane fraction was washed with deionized water, vortexed, and centrifuged for 10 secs at $112 \mathrm{~g}$-force. The hexane 
fraction was dried down using TurboVap LIV concentrator under nitrogen gas for $25 \mathrm{~min}$. The dried extract was reconstituted in methanol/dichloromethane $(1 \mathrm{~mL}, 50: 50 \mathrm{v} / \mathrm{v})$ and $100 \mu \mathrm{L}$ aliquot was injected into HPLC (Water Corporation, Milford, MA) system for carotenoids quantification. The HPLC system consisted of a C30 YMC carotenoid guard column $(4.6 \times$ $250 \mathrm{~mm}, 3 \mu \mathrm{L}$ ), binary HPLC pump (Waters 626), auto-sampler (Waters 717) and a photodiode array detector (Waters 2996). The system operated with Empower 1 software (Waters Corporation). The mobile phase comprised solvent A, composed of methanol: water $(92: 8 \mathrm{v} / \mathrm{v})$ with $10 \mathrm{mmol} / \mathrm{L}$ ammonium acetate, and solvent $\mathrm{B}$, composed of $100 \%$ methyl tertiary-butyl ether. Gradient elution was performed at a flow rate of $1 \mathrm{~mL} / \mathrm{min}$ with the following conditions: 29 min linear gradient from 83 to $59 \% \mathrm{~A}$, 6 min linear gradient from 59 to $30 \% \mathrm{~A}, 1 \mathrm{~min}$ hold at $30 \%$ A, 4 min linear gradient from 30 to $83 \% \mathrm{~A}$, and a 4 min hold at $83 \%$. Chromatograms were generated at $450 \mathrm{~nm}$, and the carotenoids were identified and quantified using the external standard method based on the calibration curve from pure standards and verification of absorption spectrum and co-elution with reference standards.

\section{Determination of Phytic Acid Content}

Phytic acid content was determined according to the method of Wheeler and Ferrel (1971). Extraction was done by mechanically shaking a mixture of $5 \mathrm{~g}$ of sample and $50 \mathrm{~mL}$ of $3 \%$ TCA for $1 \mathrm{hr}$, and then centrifuged for $15 \mathrm{~min}$ at $1,372 \mathrm{~g}$-force. A $10 \mathrm{~mL}$ aliquot of the supernatant was mixed with $4 \mathrm{~mL}$ ferric chloride solution, and the mixture was heated in a boiling water bath for $45 \mathrm{~min}$. The resulting suspension was centrifuged at 1,372 $\mathrm{g}$-force for $15 \mathrm{~min}$, and the supernatant carefully decanted. After that, the precipitate was washed twice by dispersing well in $25 \mathrm{~mL}$ of $3 \%$ TCA, heating in boiling water bath $5 \mathrm{~min}$ and centrifuging at $1,372 \mathrm{~g}$-force for $10 \mathrm{~min}$. The volume was made up to $30 \mathrm{~mL}$ with distilled water and the mixture heated in boiling water bath for $30 \mathrm{~min}$. Next, the suspension was filtered hot, and the precipitate was washed with $60 \mathrm{~mL}$ of hot distilled water. The precipitate retained on the filter paper was dissolved with $40 \mathrm{~mL}$ of hot 3.2 $\mathrm{M} \mathrm{HNO}_{3}$ into a $100 \mathrm{~mL}$ volumetric flask. A $5 \mathrm{~mL}$ aliquot was transferred to another $100 \mathrm{~mL}$ volumetric flask, and diluted to $70 \mathrm{~mL}$ with distilled water, after which $20 \mathrm{~mL}$ of $1.5 \mathrm{M} \mathrm{KSCN}$ was added, and volume made to $100 \mathrm{~mL}$ with distilled water. Absorbance was read (within $1 \mathrm{~min}$ ) at $480 \mathrm{~nm}$. A 4:6 Fe/P atomic ratio was used to calculate the phytic acid content of the sample.

\section{Determination of Tannins Content}

Tannins content of the sample was determined by the colorimetric method described by Joslyn (1970) with slight modification. A portion of the sample $(0.5 \mathrm{~g})$ was dispersed in $5 \mathrm{~mL}$ of $1 \% \mathrm{HCl}$ in methanol and left for $15 \mathrm{~min}$. The mixture was shaken and centrifuged at 1,008 g-force for $10 \mathrm{~min}$. A portion of $0.1 \mathrm{~mL}$ of the supernatant was dispensed into a test tube containing $7.5 \mathrm{~mL}$ of distilled water. Afterwards, $0.5 \mathrm{~mL}$ of FolinDennis reagent and $1 \mathrm{~mL}$ of $\mathrm{Na}_{2} \mathrm{CO}_{3}$ solution was added to the mixture, and the volume was made up to $10 \mathrm{~mL}$ with $0.9 \mathrm{~mL}$ of distilled water. The mixture was incubated for $30 \mathrm{~min}$, and the absorbance was read at $760 \mathrm{~nm}$. The tannins content, expressed in percentage, was calculated from a tannic acid standard curve.

\section{Determination of Amylose and Amylopectin Contents}

Amylose content of the samples was determined by the method described by Juliano et al. (1981). Briefly, $100 \mathrm{mg}$ of the sample was mixed with $1 \mathrm{~mL}$ of $95 \%$ ethanol and $9 \mathrm{~mL}$ of $1 \mathrm{~N} \mathrm{NaOH}$. The mixture was heated in a water bath at $100^{\circ} \mathrm{C}$ for $10 \mathrm{~min}$ to gelatinize the starch. After cooling to room temperature, the extract was diluted 10 times. Thereafter, $0.5 \mathrm{~mL}$ of the diluted extract was mixed with $0.1 \mathrm{~mL}$ of $1 \mathrm{~N}$ acetic acid solution, $0.2 \mathrm{~mL}$ of iodine solution $\left(0.2 \mathrm{~g} \mathrm{I}_{2}\right.$ in $2 \mathrm{~g} \mathrm{KI}$ in $100 \mathrm{ml}$ of distilled water) and $9.2 \mathrm{~mL}$ of distilled water. The reaction mixture was incubated at room temperature for $20 \mathrm{~min}$ for color development, after which it was shaken, and the absorbance was read at $620 \mathrm{~nm}$. Subsequently, the amylose content of the samples was calculated using amylose standard.

Amylopectin content of the samples was calculated by difference, using the formula reported by Juan et al. (2006):

$$
\text { Amylopectin (\%) = } 100-\text { amylose }(\%) \text {. }
$$

\section{Determination of Starch and Total Reducing Sugar Contents}

The starch and total reducing sugar contents were determined using the colorimetric method described earlier by Onitilo et al. (2007). A portion $(0.02 \mathrm{~g})$ of the sample was mixed with $1 \mathrm{~mL}$ of ethanol, $2 \mathrm{~mL}$ of distilled water, and $10 \mathrm{~mL}$ of hot ethanol. The mixture was centrifuged at $448 \mathrm{~g}$-force for $10 \mathrm{~min}$. The supernatant was decanted, diluted to $20 \mathrm{~mL}$ with distilled water and used for determining sugar content, while the sediment was hydrolyzed with perchloric acid and used to estimate starch content. The phenol-sulfuric reagent was used for color development, and the absorbance was read at $490 \mathrm{~nm}$. Glucose standard curve was used to calculate sugar and starch contents, expressed in percentage.

\section{Determination of Pasting Properties}

The pasting properties of the samples were determined using a Rapid Visco Analyzer (RVA) (RVA-4500, Perten Scientific instruments, Springfield, IL) as reported by Deffenbaugh and Walker (1989). The RVA was equipped with a personal computer (PC) containing Thermocline software. The pasting characteristics of a suspension of $3.42 \mathrm{~g}$ sample in $25 \mathrm{~mL}$ of distilled water, including peak viscosity, trough, breakdown, final viscosity, set back, peak time, and pasting temperature, was read on the PC with the help of the Thermocline software. The results were expressed in Rapid Visco Analyzer units (RVU).

\section{Statistical Analysis of Results}

Data from this study were subjected to analysis of variance (ANOVA) using the XLSTAT-Student 2020 Statistical software package. There was no data transformation carried out on the collected data. The means were separated using Tukey's Least significant difference (LSD) test to identify differences among genotypes at a confidence interval of $95 \%$. Pearson correlation 
TABLE 1 | Carotenoids profile of Striga-resistant yellow-orange maize hybrids grown at Zaria and Saminaka $(N=64)$.

\begin{tabular}{|c|c|c|c|c|c|c|c|c|c|c|}
\hline Variable & Lut & Zeax & $\beta \mathbf{C X}$ & $\alpha \mathbf{C}$ & $13-c i s-\beta C$ & trans $-\beta \mathrm{C}$ & $9-c i s-\beta \mathrm{C}$ & Total $\beta \mathrm{C}$ & Total Xan & pVAC \\
\hline Range $(\mu \mathrm{g} / \mathrm{g})$ & $2.6-9.6$ & $2.1-9.7$ & $0.7-2.9$ & $0.0-0.6$ & $0.3-0.9$ & $0.7-2.0$ & $0.3-1.2$ & $1.4-4.1$ & $5.4-17.1$ & $1.9-5.3$ \\
\hline Average $(\mu \mathrm{g} / \mathrm{g})$ & 6.2 & 4.7 & 1.4 & 0.3 & 0.6 & 1.3 & 0.7 & 2.5 & 10.9 & 3.4 \\
\hline P genotype & $\star \star *$ & NS & NS & NS & NS & * & NS & * & ** & NS \\
\hline
\end{tabular}

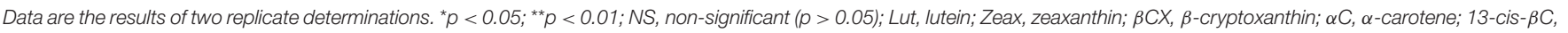
13-cis- $\beta$-carotene; trans- $\beta$ C, all-trans- $\beta$-carotene; 9-cis- $\beta$ C, 9-cis- $\beta$-carotene; $\beta C$, $\beta$-carotene; pVAC, provitamin A carotenoids.

TABLE 2 | Phytate and tannin levels of Striga-resistant yellow-orange maize hybrids grown at Zaria and Saminaka $(N=64)$.

\begin{tabular}{lcc}
\hline Variable & Tannins & Phytate \\
\hline Range (\%) & $2.1-7.3$ & $0.5-7.1$ \\
Average (\%) & 4.2 & 4.0 \\
P Genotype & $* * *$ & $* \star *$ \\
\hline
\end{tabular}

Data are the results of two replicate determinations. ${ }^{\star * \star} p<0.0001$.

coefficients between the measured components were determined using the XLSTAT software.

\section{RESULTS}

\section{Carotenoids Profile of Striga-Resistant Yellow-Orange Maize Hybrids}

Carotenoids profile of the 16 Striga-resistant yellow-orange maize hybrids grown in two replications at Zaria and Saminaka are presented in Table 1. The principal carotenoids in the maize hybrids, as revealed by HPLC fingerprinting, were lutein, zeaxanthin, $\beta$-cryptoxanthin and $\beta$-carotene. In addition to these major carotenoids, $\alpha$-carotene was also detected. The ranges of the carotenoids $(\mu \mathrm{g} / \mathrm{g})$ varied from 2.6 to 9.6 for lutein, from 2.1 to 9.7 for zeaxanthin, from 0.7 to 2.9 for $\beta$-cryptoxanthin, from 1.4 to 4.1 for $\beta$-carotene and 0.0 to 0.6 for $\alpha$-carotene; with total xanthophylls and provitamin A carotenoids (pVAC) ranging from 5.4 to 17.1 and 1.4 to $4.1 \mu \mathrm{g} / \mathrm{g}$, respectively. Hybrid had a significant effect only on the levels of lutein and total xanthophylls $(p<0.01)$, all-trans- $\beta$-carotene and total $\beta$-carotene $(p<0.05)$.

\section{Tannins and Phytate Levels of Striga-Resistant Yellow-Orange Maize Hybrids}

The tannins and phytate levels of the Striga-resistant yelloworange maize hybrids are presented in Table 2. Across the two locations (Zaria and Saminaka), the level of tannins ranged from 2.1 to $7.3 \%$, with an overall mean of $4.2 \%$; while phytate level ranged from 0.5 to $7.1 \%$, with an overall mean of $4.0 \%$. Hybrid had a significant effect $(p<0.001)$ on the levels of phytate and tannins.
TABLE 3 | Carbohydrate profile of Striga-resistant yellow-orange maize hybrids grown at Zaria and Saminaka $(N=64)$.

\begin{tabular}{lcccc}
\hline Summary & Starch & Sugar & Amylose & Amylopectin \\
\hline Range (\%) & $40.1-88.9$ & $1.1-6.5$ & $15.0-34.1$ & $65.9-85.0$ \\
Average (\%) & 67.2 & 2.7 & 23.0 & 77.0 \\
P Genotype & $* \star *$ & $* *$ & $* *$ & $* *$ \\
\hline
\end{tabular}

Data are the results of two replicate determinations. ${ }^{* \star} p<0.01$; ${ }^{\star \star \star} p<0.0001$.

\section{Carbohydrate Profile of Striga-Resistant Yellow-Orange Maize Hybrids}

The carbohydrate profile of the Striga-resistant yellow-orange maize hybrids grown at Zaria and Saminaka are presented in Table 3. Across the two locations, starch content ranged from 40.1 to $88.9 \%$, with an overall mean of $67.2 \%$. Sugar content with an overall mean of $2.7 \%$, ranged from 1.1 to $6.5 \%$; amylose content ranged from 15 to $34.1 \%$, with an overall mean of $23 \%$; while amylopectin content ranged from 65.9 to $85.0 \%$, with an overall mean of $77.0 \%$. The levels of starch, sugar, amylose and amylopectin were significantly $(p<0.05)$ affected by hybrid.

\section{Pasting Properties of Striga-Resistant Yellow-Orange Maize Hybrids}

The pasting properties of the Striga-resistant yellow-orange maize hybrids grown at Zaria and Saminaka are presented in Table 4. The pasting properties were in the ranges of 57.8 to $114.9,54.6$ to $109.5,1.0$ to $8.2,120.3$ to $261.6,64.5$ to 152.4 RVU for peak, trough, breakdown, final and setback viscosities, respectively; 6.6 to $7.0 \mathrm{~min}$ and 80.8 to $88.2^{\circ} \mathrm{C}$ for peak time and pasting temperature, respectively. Hybrid had a significant effect $(p<0.05)$ on the pasting parameters except for the breakdown viscosity and peak time.

\section{Correlations of the Bioactive Components, Carbohydrate Profile and Pasting Properties of Striga-Resistant Yellow-Orange Maize Hybrids}

The correlations of the bioactive components, carbohydrate profile and pasting properties of the Striga-resistant yelloworange maize hybrids are presented in Table 5. Amylose was significantly and positively correlated $(p<0.05)$ with each of total xanthophylls, $\beta$-carotene, pVAC, phytate and pasting temperature $(r: 0.3,0.3,0.4,0.3$, and 0.3 , respectively). Significant 
TABLE 4 | Pasting properties of Striga-resistant yellow-orange maize hybrids grown at Zaria and Saminaka $(N=64)$.

\begin{tabular}{|c|c|c|c|c|c|c|c|}
\hline Variable & Peak (RVU) & Trough (RVU) & Breakdown (RVU) & Final Visc (RVU) & Setback (RVU) & Peak time (min) & Pasting temp $\left({ }^{\circ} \mathbf{C}\right)$ \\
\hline Range & $57.8-114.9$ & $54.6-109.5$ & $1.0-8.2$ & 120.3-261.6 & $64.5-152.4$ & $6.6-7.0$ & $80.8-88.2$ \\
\hline Average & 91.0 & 86.4 & 4.6 & 195.3 & 108.9 & 7.0 & 83.7 \\
\hline P Genotype & $\star *$ & ** & NS & 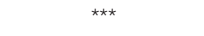 & $* \star *$ & NS & 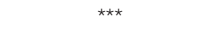 \\
\hline
\end{tabular}

Data are the results of two replicate determinations. ${ }^{* \star} p<0.01 ;{ }^{\star \star \star} p<0.0001 ; N S$, non-significant $(p>0.05)$.

TABLE 5 | Correlation between bioactive components, carbohydrate profile and pasting properties of Striga-resistant yellow-orange maize hybrids grown at Zaria and Saminaka.

\begin{tabular}{|c|c|c|c|c|c|c|c|c|c|c|c|c|c|c|}
\hline Variables & Amylopectin ${ }^{a}$ & Phytate $^{a}$ & Tannins $^{a}$ & Starch $^{a}$ & Breakdown $^{\text {b }}$ & $\begin{array}{l}\text { Total } \\
\text { Xanc }\end{array}$ & pVAC $^{c}$ & $\begin{array}{l}\text { Total } \\
\beta \mathrm{C}^{\mathrm{c}}\end{array}$ & $\begin{array}{l}\text { Pasting } \\
\text { temp }\end{array}$ & Set-back ${ }^{b}$ & $\begin{array}{l}\text { Final } \\
\text { visc }^{\mathbf{b}}\end{array}$ & Trough $^{\mathbf{b}}$ & $\begin{array}{c}\text { Peak } \\
\text { time }\end{array}$ & Sugar ${ }^{a}$ \\
\hline Amylose ${ }^{a}$ & $-1.0^{\star \star \star}$ & $0.3^{\star}$ & 0.0 & 0.0 & 0.0 & $0.3^{\star}$ & $0.4^{\star \star}$ & $0.3^{\star \star}$ & $0.3^{\star \star}$ & -0.2 & -0.2 & -0.1 & 0.0 & 0.0 \\
\hline Amylopectin ${ }^{a}$ & & $-0.3^{*}$ & 0.0 & 0.0 & 0.0 & $-0.3^{*}$ & $-0.4^{\star \star}$ & $-0.3^{\star \star}$ & $-0.3^{\star \star}$ & 0.2 & 0.2 & 0.1 & 0.0 & 0.0 \\
\hline Phytate $^{a}$ & & & -0.1 & 0.0 & $-0.3^{*}$ & -0.1 & 0.1 & 0.1 & 0.1 & 0.0 & -0.1 & -0.1 & 0.0 & 0.1 \\
\hline Tannins $^{a}$ & & & & $0.3^{\star \star}$ & 0.2 & 0.0 & 0.2 & 0.1 & 0.2 & -0.1 & -0.1 & -0.1 & 0.0 & 0.0 \\
\hline Starch $^{a}$ & & & & & $0.3^{\star}$ & 0.0 & 0.2 & 0.2 & $0.3^{\star \star}$ & -0.1 & -0.1 & -0.2 & 0.1 & 0.2 \\
\hline Breakdown ${ }^{b}$ & & & & & & $0.3^{\star}$ & $0.4^{\star \star}$ & $0.4^{\star \star}$ & $0.5^{\star \star \star}$ & 0.0 & 0.0 & 0.0 & -0.1 & -0.1 \\
\hline Total Xan ${ }^{c}$ & & & & & & & $0.7^{\star \star \star}$ & $0.7^{\star \star \star}$ & $0.3^{\star}$ & 0.0 & 0.0 & 0.0 & 0.0 & -0.2 \\
\hline $\mathrm{pVAC}^{\mathrm{c}}$ & & & & & & & & $1.0^{\star \star \star}$ & $0.5^{\star \star \star}$ & $-0.2^{*}$ & -0.2 & -0.2 & 0.0 & -0.1 \\
\hline Total $\beta \mathrm{C}^{\mathrm{C}}$ & & & & & & & & & $0.5^{\star \star \star}$ & -0.2 & -0.2 & -0.2 & 0.0 & -0.1 \\
\hline Pasting temp ${ }^{d}$ & & & & & & & & & & $-0.3^{\star \star}$ & $-0.3^{\star \star}$ & $-0.3^{\star \star}$ & 0.2 & 0.1 \\
\hline Set-back ${ }^{b}$ & & & & & & & & & & & $1.0^{\star \star \star}$ & $0.9^{\star \star \star}$ & -0.2 & 0.0 \\
\hline Final visc ${ }^{b}$ & & & & & & & & & & & & $1.0^{\star \star \star}$ & -0.2 & 0.0 \\
\hline Trough ${ }^{b}$ & & & & & & & & & & & & & -0.2 & 0.0 \\
\hline Peak time $^{e}$ & & & & & & & & & & & & & & -0.1 \\
\hline
\end{tabular}

a: \%; ${ }^{b}: R V U ;{ }^{c}: \mu \mathrm{g} / \mathrm{g} ;{ }^{d}:{ }^{\circ} \mathrm{C} ;{ }^{e}:$ min; ${ }^{*} p<0.05 ;{ }^{* *} p<0.01 ;{ }^{* * *} p<0.0001 ;$ NS, non-significant $(p>0.05) ;$ Xan, xanthophylls; pVAC, provitamin A carotenoids; $\beta C, \beta-$ carotene.

and positive correlations $(p<0.05)$ were also observed between tannins and starch $(r: 0.3)$; starch and pasting temperature $(r$ : $0.3)$; provitamin A carotenoids and pasting temperature $(p<$ $0.001 ; r$ : 0.5$)$. In addition, breakdown viscosity significantly correlated $(p<0.05)$ with each of total xanthophylls $(r: 0.3)$, provitamin A carotenoids $(p<0.01 ; r$ : 0.4$)$, total $\beta$-carotene $(p<0.01 ; r: 0.4)$, and pasting temperature $(p<0.001 ; r: 0.5)$. Total xanthophylls also significantly and positively correlated with each of provitamin A carotenoids $(p<0.001 ; r$ : 0.7$)$ and pasting temperature $(p<0.05 ; r$ : 0.3$)$. However, no significant correlation was observed between final viscosity and any of total xanthophylls and pVAC. Among the pasting properties, pasting temperature significantly correlated $(p<0.05)$ negatively with each of set-back, final and trough viscosities $(r:-0.3)$. Set-back viscosity also correlated highly $(p<0.001)$ with each of final $(r$ : $1.0)$ and trough $(r: 0.9)$ viscosities.

\section{DISCUSSION}

\section{Carotenoids Profile of Striga-Resistant Yellow-Orange Maize Hybrids}

The carotenoids composition of the Striga-resistant yelloworange maize hybrids in this study (Table 1) is similar to that of orange maize genotypes previously reported by Muzhingi et al. (2016) and Alamu et al. (2018). Generally, xanthophylls (lutein and zeaxanthin) were more predominant than provitamin $\mathrm{A}$ carotenoids ( $\beta$-cryptoxanthin and $\beta$-carotene), with zeaxanthin as the most abundant carotenoid. This is consistent with previous findings on the carotenoids composition of orange maize genotypes (Ortiz et al., 2016; Taleon et al., 2017). However, the levels of $\beta$-cryptoxanthin $(0.7-2.9 \mu \mathrm{g} / \mathrm{g})$ and $\beta$-carotene (1.4$4.1 \mu \mathrm{g} / \mathrm{g})$ quantified in the Striga-resistant yellow-orange maize hybrids in this study are lower than the values reported for provitamin A carotenoids biofortified orange maize hybrids (1.38.8 and $1.3-8.0 \mu \mathrm{gg}-1$ for $\beta$-cryptoxanthin and $\beta$-carotene, respectively) (Muzhingi et al., 2016). However, the presence of these provitamin A carotenoids in the Striga-resistant yelloworange maize hybrids suggests that they can be targeted for provitamin A carotenoids improvement, and consequently, for vitamin $\mathrm{A}$ alleviation. In addition to provitamin $\mathrm{A}$ activity, $\beta$ cryptoxanthin had been earlier reported to significantly reduce the risk of T2D (Montonen et al., 2004), and attenuate insulin resistance (Ni et al., 2015). It suggests that Striga-resistant yelloworange maize hybrids with improved $\beta$-cryptoxanthin level may be beneficial for mitigating the hyperglycaemia associated with diabetic conditions.

Among the carotenoids, only the levels of lutein and total xanthophylls $(p<0.01)$, all-trans- $\beta$-carotene and total $\beta$ carotene varied significantly $(p<0.05)$ across the hybrids. Contrary to this finding, previous studies had indicated that the levels of all carotenoids in biofortified orange maize hybrids were significantly affected by genotype (Muzhingi et al., 2016; 
Alamu et al., 2018). This discrepancy may be attributed to the differences that may exist in the genetic makeup of the Strigaresistant yellow-orange maize hybrids and biofortified orange maize genotypes.

\section{Tannin and Phytate Levels of Striga-Resistant Yellow-Orange Maize Hybrids}

Tannins, a class of polyphenolic compounds, and phytate are prominent for their antioxidant properties. Tannins also possess other health benefits such as anti-obesity, antidiabetic and anti-hypertensive (Irondi et al., 2018), as well as anti-carcinogenic and antimutagenic potentials due to their antioxidative property (Chung et al., 1998). Similarly, phytate was reported to exhibit an inhibitory effect against the development of kidney stone (Dost and Tokul, 2006) and anticancer properties (Vucenik and Shamsuddin, 2003) as earlier mentioned. The ranges of tannins and phytate observed in this study (2.1-7.3\% and $0.5-7.1 \%$, respectively), suggest that the Striga-resistant yellow-orange maize hybrids may serve as a rich food source of tannins and phytate and their potential health benefits.

\section{Carbohydrate Profile of Striga-Resistant Yellow-Orange Maize Hybrids}

In this study, amylopectin contents were consistently higher than amylose contents across the genotypes from the two locations (Table 3). The observation corroborated the existing report that amylopectin is the predominant constituent of most plant starches (Yotsawimonwat et al., 2008; Irondi et al., 2019). Furthermore, amylose and amylopectin levels of starches have an impact on their glycemic index; with higher amylopectin and a lower amylose contents resulting in a higher glycemic index (Shanita et al., 2011). This is due to the ease of digestion of amylopectin by $\alpha$-amylase in human duodenum relative to amylose (Birt et al., 2013). Amylose and amylopectin levels also affect the functional properties of flours and their potential food and industrial applications (Irondi et al., 2017). Carbohydrates are essential indicators of the potential health benefits and food applications of cereals. Available carbohydrates (sugars and starch) primarily provide energy to cells of the body, especially the brain cells, which are entirely dependent on carbohydrate. Sugars are also involved in controlling insulin metabolism, blood glucose level and intestinal microflora activity (Hounsome et al., 2008).

\section{Pasting Properties of Striga-Resistant Yellow-Orange Maize Hybrids}

Pasting properties represent the changes in the physical and chemical structures of starch in suspension when subjected to a definite cycle of heating and cooling under shear forces (Liao and $\mathrm{Wu}, 2016$; Irondi et al., 2017). They play an essential role in the applications of starch in the food industry and other industries (Berski et al., 2011). The variation in the pasting properties of the Striga-resistant yellow-orange maize hybrids might be attributed to their differential starch composition, as earlier suggested by
Ortiz et al. (2019). It is known that starch containing more branched amylopectin achieves high peak viscosities due to its propensity to absorb and retain more water (Gayral et al., 2015). Peak viscosity is indicative of the ability of starch granules to swell freely before their physical breakdown, and it is associated with the final product quality (Alamu et al., 2017).

On the other hand, final viscosity is the pasting parameter mostly used to determine the quality of a given starch/flour sample. It is the change in viscosity after cooked starch is held at $50^{\circ} \mathrm{C}$, indicating how stable the cooked starch as well as the resistance of the paste to shear force during stirring (Maziya-Dixon et al., 2005). Set back viscosity indicates the paste's stability and its propensity to retrograde (Liang and King, 2003). It defines the viscosity of the cooked paste after cooling to $50^{\circ} \mathrm{C}$, during which the amylose and amylopectin components in the starch retrograde or re-associate. Hence, a high setback viscosity indicates a higher tendency of starch molecules to disperse more readily in hot paste and re-associate during cooling (Chinma et al., 2010). On the other hand, a high pasting temperature suggests that the flour/starch of Strigaresistant yellow-orange maize hybrids may have short cooking time. The attainment of pasting temperature, the minimum temperature needed to cook a starchy sample, is necessary for the swelling, gelatinization and pasting of starch during food processing (Offia-Olua, 2014).

\section{Correlations of the Bioactive Components, Carbohydrate Profile and Pasting Properties of Striga-Resistant Yellow-Orange Maize Hybrids}

As presented in Table 5, there were correlations between some of the bioactive components, carbohydrates and pasting properties of the Striga-resistant yellow-orange maize hybrids. The correlations observed between the carotenoids in the maize hybrids agree with the reports of some previous studies. Menkir et al. (2014) found a significant and negative correlation between provitamin A carotenoids and each of lutein and $\alpha$ carotene, and a significant and positive correlation between provitamin A carotenoids and each of zeaxanthin, $\beta$-carotene and $\beta$-cryptoxanthin in inbred lines of orange and yellow endosperm maize. Similarly, Muzhingi et al. (2016) reported a positive correlation between $\beta$-cryptoxanthin and each of zeaxanthin and lutein. The positive correlation between amylose and pasting temperature observed in this study is in agreement with the findings of Charles et al. (2005) that high amylose level is correlated with increased pasting temperature. The observed correlations may provide useful information on the possibility of simultaneously or independently improving the chemical constituents (in this case, bioactive components and carbohydrates) and the pasting properties of the Striga-resistant yellow-orange maize hybrids during breeding. For instance, the significant and positive correlations between amylose and each of total xanthophylls, $\beta$-carotene, pVAC and phytate suggest that the levels of these constituents may be simultaneously targeted for improvement during breeding. 


\section{CONCLUSIONS}

The Striga-resistant yellow-orange maize hybrids evaluated in this study contained appreciable levels of bioactive constituents (carotenoids, tannins and phytate), carbohydrates (starch, free sugar, amylose and amylopectin) and pasting properties. Hybrid (genotype) was significant in determining the levels of $\beta$-carotene, total xanthophylls, tannins, phytate, sugar, amylose, amylopectin, peak and final viscosities of the Striga-resistant yellow-orange maize hybrids. Significant correlations were also observed between the various chemical constituents (bioactive components and carbohydrates) and the pasting properties of the Striga-resistant yellow-orange maize hybrids. Therefore, the Striga-resistant yelloworange maize hybrids have a right combination of bioactive constituents, carbohydrate profile and pasting properties, which provide insight into their potential health benefits and food applications.

\section{DATA AVAILABILITY STATEMENT}

The raw data supporting the conclusions of this article will be made available by the authors, without undue reservation.

\section{REFERENCES}

Agarwal, L. S., and Rao, A. V. (2000). Carotenoids and chronic diseases. Drug Metab. Drug Interact. 17, 189-210. doi: 10.1515/DMDI.2000.17.1-4.189

Alamu, E. O., Maziya-Dixon, B., and Dixon, A. G. (2017). Evaluation of proximate composition and pasting properties of high quality cassava flour (HQCF) from cassava genotypes (Manihot esculenta Crantz) of $\beta$-carotene-enriched roots. LWT - Food Sci. Technol. 86, 501-506. doi: 10.1016/j.lwt.2017.08.040

Alamu, E. O., Maziya-Dixon, B., Menkir, A., and Olaofe, O. (2018). Bioactive compounds of freshly harvested open pollinated varieties (OPV) of orange maize (Zea mays): varietal, maturity, and boiling methods effects. Cogent Chem. 4:1507489. doi: 10.1080/23312009.2018.1507489

Benjamin, A., Bafour, B., Daniel, N., Richard, A., and Morakinyo, A. B. (2019). Testcross performance and combining ability of early maturing maize inbreds under multiple-stress environments. Nat. Res. 9:13809. doi: 10.1038/s41598-019-50345-3

Berski, W., Ptaszek, A., Ptaszek, P., Ziobro, R., Kowalski, G., Grzesik, M., et al. (2011). Pasting and rheological properties of oat starch and its derivatives. Carbohydr. Polym. 83, 665-671. doi: 10.1016/j.carbpol.2010.08.036

Birt, D. F., Boylston, T., Hendrich, S., Jane, J. L., Hollis, J., Li, L., et al. (2013). Resistant starch: promise for improving human health. Adv. Nutr. 4, 587-601. doi: 10.3945/an.113.004325

Bohn, L., Meyer, A. S., and Rasmussen, S. K. (2008). Phytate: impact on environment and human nutrition. A challenge for molecular breeding. J. Zhejiang Univ. Sci. B 9, 165-191. doi: 10.1631/jzus.B0710640

Charles, A. L., Chang, Y. H., Ko, W. C., Sriroth, K., and Huang, T. C. (2005). Influence of amylopectin structure and amylose content on the gelling properties of five cultivars of cassava starches. J. Agric. Food Chem. 53, 2717-2725. doi: 10.1021/jf048376+

Chinma, C. E., Abu, J. O., and Ojo, J. A. (2010). Chemical, functional and pasting properties of starches from brown and yellow tigernuts. Niger. Food. J. 28, 1-13.

Chung, K. T., Wong, T. Y., Wei, C. I., Huang, Y. W., and Lin, Y. (1998). Tannins and human health: a review. Crit. Rev. Food Sci. Nutr. 38, 421-464. doi: 10.1080/10408699891274273

Cissé, M., Zoue, L. T., Soro, Y. R., Megnanou, R., and Niamke, S. (2013). Physicochemical and functional properties of starches of two quality protein

\section{AUTHOR CONTRIBUTIONS}

EI, EAl, and EAj designed the study. AE carried out the laboratory analyses. $\mathrm{EAl}$ analyzed the data. $\mathrm{EI}$ and $\mathrm{AE}$ wrote the manuscript. BM-D provided laboratory facilities for the study. AM provided the plant materials for the study. EAl and AM reviewed and edited the manuscript. All authors contributed to the article and approved the submitted version.

\section{FUNDING}

This research was funded by the International Institute of Tropical Agriculture (IITA) Ibadan, Nigeria and Bill \& Melinda Gates Foundation (BMGF) through a grant OPP1178942.

\section{ACKNOWLEDGMENTS}

The authors acknowledged the support of International Institute of Tropical Agriculture (IITA) Ibadan, Nigeria, Bill \& Melinda Gates Foundation (BMGF) and CGIAR-CRP Maize. Also, the support of Mr. Adesokan Michael, Mr. Tayo Ojo, the entire staff of Food and Nutrition Sciences Laboratory and that of Maize Breeding Unit, IITA, Ibadan, Nigeria, is also acknowledged.

maize (QPM) grown in Côte d'Ivoire. J. Appl. Biosci. 66, 5130-5139. doi: 10.4314/jab.v66i0.95010

de la Parra, C., Saldivar, S. O., and Liu, R. H. (2007). Effect of processing on the phytochemical profiles and antioxidant activity of corn for production of masa, tortillas, and tortilla chips. J. Agric. Food Chem. 55, 4177-4183. doi: 10.1021/jf063487p

Deffenbaugh, L. B., and Walker, C. E. (1989). Comparison of starch pasting properties in the brabender viscoamylograph and the Rapid visco-Analyzer. Cereal Chem. 66:499.

Dost, K., and Tokul, O. (2006). Determination of phytic acid in wheat and wheat products by reverse phase high performance liquid chromatography. Anal. Biochem. 119, 413-417. doi: 10.1016/j.aca.2005.11.035

Gammone, M. A., Pluchinotta, F. R., Bergante, S., Tettamanti, G., and D'Orazio, N. (2017). Prevention of cardiovascular diseases with carotenoids. Front Biosci. 9, 165-171. doi: 10.2741/s480

Gayral, M., Bakan, B., Dalgalarrondo, M., Elmorjani, K., Delluc, C., Brunet, S., et al. (2015). Lipid partitioning in maize (Zea mays L.) endosperm highlights relationships among starch lipids, amylose, and vitreousness. J. Agric. Food Chem. 63, 3551-3558. doi: 10.1021/acs.jafc.5b00293

Horstmann, S. W., Belz, M. C. E., Heitmann, M., Zannini, E., and Arendt, E. K. (2016). Fundamental study on the impact of gluten-free starches on the quality of gluten-free model breads. Foods 5:30. doi: 10.3390/foods50 20030

Hounsome, N., Hounsome, B., Tomos, D., and Edwards-Jones, G. (2008). Plant metabolites and nutritional quality of vegetables. J. Food Sci. 73, R48-R65. doi: 10.1111/j.1750-3841.2008.00716.x

Howe, J. A., and Tanumihardjo, S. A. (2006). Evaluation of analytical methods for carotenoid extraction from biofortified maize (Zea mays Sp). J. Agric. Food Chem. 54, 7992-7997. doi: 10.1021/jf062256f

$\mathrm{Hu}$, Q. P., and Xu, J. G. (2011). Profiles of carotenoids, anthocyanins, phenolics, and antioxidant activity of selected color waxy corn grains during maturation. J. Agric. Food Chem. 59, 2026-2033. doi: 10.1021/jf104149q

$\mathrm{Hu}$, Y., Burucs, Z., and Schmidhalter, U. (2008). Effect of foliar fertilization application on the growth and mineral nutrient content of maize seedlings under drought and salinity. Soil Sci. Plant Nutr. 54, 133-141. doi: 10.1111/j.1747-0765.2007.00224.x 
Ibrahim, K. E., and Juvik, J. A. (2009). Feasibility for improving phytonutrient content in vegetable crops using conventional breeding strategies: case study with carotenoids and tocopherols in sweet corn and broccoli. J. Agric. Food Chem. 57, 4636-4644. doi: 10.1021/jf900260d

Irondi, E. A., Awoyale, W., Oboh, G., and Boligon, A. A. (2017). Effect of mango kernel flour addition on the phenolics profile, antioxidant activity and pasting properties of wheat flour. J. Food Meas. Charact. 11, 2202-2210. doi: 10.1007/s11694-017-9605-3

Irondi, E. A., Awoyale, W., Oboh, G., and Boligon, A. A. (2019). Phenolics composition, antioxidant and pasting properties of highquality cassava flour substituted with Brachystegia eurycoma seed flour. Ann. Univ Dunarea Jos Galati Fascicle VI - Food Technol. 43, 9-23. doi: 10.35219/foodtechnology.2019.1.01

Irondi, E. A., Mohammed, R. O., Balogun, A. F., Tajudeen, H. I., and Aleshinloye, O. M. (2018). Antioxidant and modulatory properties of kernel flour extracts of three Nigerian local mango varieties on enzymes relevant to metabolic syndrome. Oxid. Antioxid. Med. Sci. 8, 1-10. doi: 10.5455/oams.20180927065758

Joslyn, M. A. (ed.). (1970). Methods in Food Analysis. Physical, Chemical and Instrumental Methods of Analysis, 2nd Edn. Academic Press.

Juan, G., Luis, A., and David, B. (2006). Isolation and molecular characterization of Makal (Xanthosoma yucatanensis) starch. Starch 58, 300-307. doi: 10.1002/star.200500451

Juliano, B. O., Perez, C. M., and Blakeney, B. (1981). International cooperative testing on the amylose content of milled rice. Starch 33, 157-162. doi: 10.1002/star.19810330504

Karim, A. A., Norziah, M. H., and Seow, C. C. (2000). Methods for the study of starch retrogradation. Food Chem. 71, 9-36. doi: 10.1016/S0308-8146(00)00130-8

Kumar, D., and Jhariya, A. N. (2013). Nutritional, medicinal and economical importance of corn: a mini review. Res. J. Pharm. Sci. 2, 7-8.

Liang, X., and King, J. M. (2003). Pasting and crystalline property differences of commercial and isolated rice starch with added amino acids. J. Food Sci. 68, 832-838. doi: 10.1111/j.1365-2621.2003.tb08251.x

Liao, L., and Wu, W. (2016). Fermentation effect on the properties of sweet potato starch and its noodle's quality by Lactobacillus plantarum. J. Food Process Eng. 40:e12460. doi: 10.1111/jfpe.12460

Maziya-Dixon, B., Adebowale, A. A., Onabanjo, O. O., and Dixon, A. G. O. (2005). Effect of variety and drying methods on physico-chemical properties of high quality cassava flour from yellow cassava roots. Afr. Crop Sci. Conf. Proc. 7, 635-641.

Menkir, A. (2006). Assessment of reactions of diverse maize inbred lines to Striga hermonthica (Del.) benth. Plant Breeding. 125, 131-139. doi: 10.1111/j.1439-0523.2006.01175.x

Menkir, A. (2014). Nigeria releases first generation of herbicide-resistant hybrids. Int. Inst. Trop. Agric. Bull. 2231, 23-27. Available online at: https://www.iita.org/wp-contentuploads/2016/12/The-Bulletin-23-27-June2014-No.-2231-1.pdf

Menkir, A., Franco, J., Adepoju, A., and Bossey, B. (2012). Evaluating consistency of resistance reactions of open-pollinated maize cultivars (Del.) Benth under artificial infestation. Crop Sci. 52, 1051-1060. doi: 10.2135/cropsci2012.05.0307

Menkir, A., Gedil, M., Tanumihardjo, S., Adepoju, A., and Bossey, B. (2014). Carotenoid accumulation and agronomic performance of maize hybrids involving parental combinations from different marker-based groups. Food Chem. 148, 131-137. doi: 10.1016/j.foodchem.2013.09.156

Menkir, A., Weiping, L., Wendy, S. W., Maziya-Dixon, B., and Rocheford, T. (2008). Carotenoids diversity in tropical-adapted orange maize inbred lines. Food Chem. 109, 521-529. doi: 10.1016/j.foodchem.2008.01.002

Montonen, J., Knekt, P., Jarvinen, R., and Reunanen, A. (2004). Dietary antioxidant intake and risk of type 2 diabetes. Diabetes Care. 27, 362-366. doi: $10.2337 /$ diacare.27.2.362

Muzhingi, T., Palacios-Rojas, N., Miranda, A., Cabrera, M. L., Yeum, K. J., and Tang, G. (2016). Genetic variation of carotenoids, vitamin E and phenolic compounds in provitamin A biofortified maize. J. Sci. Food Agric. 97, 793-801. doi: 10.1002/jsfa.7798

Ni, Y., Nagashimada, M., Zhan, L., Nagata, N., Kobori, M., Sugiura, M., et al. (2015). Prevention and reversal of lipotoxicity-induced hepatic insulin resistance and steatohepatitis in mice by an antioxidant carotenoid, $\beta$ cryptoxanthin. Endocrinol 156, 987-999. doi: 10.1210/en.2014-1776

Offia-Olua, B. I. (2014). Chemical, functional and pasting properties of wheat (Triticum spp)-walnut (Juglans regia) flour. Food Nutr. Sci. 5, 1591-1604. doi: $10.4236 /$ fns. 2014.516172

Onitilo, A. A., Sanni, L. O., Daniel, I., and Maziya-Dixon, B. (2007). Physicochemical and functional properties of native starches from cassava varieties in Southwest Nigeria. J. Food Agric. Environ. 5, 108-114. doi: 10.1080/10942910601048994

Ortiz, D., Nkhata, S. G., Rocheford, T., and Ferruzzi, M. G. (2019). Steeping of biofortified orange maize genotypes for Ogi production modifies pasting properties and carotenoid stability. Agron 9:771. doi: 10.3390/agronomy9110771

Ortiz, D., Rocheford, T., and Ferruzi, M. G. (2016). Influence of temperature and humidity on the stability of carotenoids in biofortified maize (Zea mays L.) genotypes during controlled post-harvest storage. J. Agric. Food Chem. 64, 2727-2736. doi: 10.1021/acs.jafc.5b 05698

Polycarp, D., Afoakwa, E. O., Budu, A. S., and Otoo, E. (2012). Characterization of chemical composition and anti-nutritional factors in seven species within the Ghanaian yam (Dioscorea) germplasm. Int. Food Res. J. 19, 985-992.

Seifried, H. E., Anderson, D. E., Fisher, E. I., and Milner, J. A. (2007). A review of the interaction among dietary antioxidants and reactive oxygen species. J. Nutr. Biochem. 18, 567-579. doi: 10.1016/j.jnutbio.2006. 10.007

Shanita, S. N., Hasnah, H., and Khoo, C. W. (2011). Amylose and amylopectin in selected Malaysian foods and its relationship to glycemic index. Sains Malaysiana. 40, 865-870.

Sugiura, M., Nakamura, M., Ogawa, K., Ikoma, Y., and Yano, M. (2015). Highserum carotenoids associated with lower risk for developing type 2 diabetes among Japanese subjects: mikkabi cohort study. BMJ Open Diabetes Res. Care. 3:e000147. doi: 10.1136/bmjdrc-2015-000147

Taleon, V., Mugode, L., Cabrera-Soto, L., and Palacios-Rojas, N. (2017). Carotenoid retention in biofortified maize using different postharvest storage and packaging methods. Food Chem. 232, 60-66. doi: 10.1016/j.foodchem.2017.03.158

Vucenik, I., and Shamsuddin, A. M. (2003). Cancer inhibition by inositol hexaphosphate (ip6) and inositol: from laboratory to clinic. J. Nutri. 133(Suppl. 11), 3778S-3784S. doi: 10.1093/jn/133.11.3778S

Wheeler, E. L., and Ferrel, R. E. (1971). A method for phytic acid determination in wheat fractions. Cereal Chem. 48, 312-316.

Yotsawimonwat, S., Sriroth, K., Kaewvichit, S., Piyachomkwan, K., Jane, J. L., and Sirithunyalug, J. (2008). Effect of $\mathrm{pH}$ on complex formation between debranched waxy rice starch and fatty acids. Int. J. Biol. Macromol. 43, 94-99. doi: 10.1016/j.ijbiomac.2008.03.006

Yousaf, M. I., Hussain, K., Hussain, S., Ghani, A., Shehzad, A., Mumtaz, A., et al. (2020). Seasonal influence, heat unit accumulation and heat use efficiency in relation to maize grain yield in Pakistan. Maydica 64:9.

Zilić, S., Serpen, A., Akillioglu, G., Gökmen, V., and Vančetović, J. (2012). Phenolic compounds, carotenoids, anthocyanins, and antioxidant capacity of colored maize (Zea mays L.) kernels. J. Agric. Food Chem. 60, 1224-1231. doi: 10.1021/jf204367z

Zilic, S. M., Milasinovic, D., Terzic, M., and Barac, D. (2011). Grain characteristics and composition of maize specialty hybrids Spanish. J. Agric. Res. 9, 230-241. doi: 10.5424/sjar/20110901-053-10

Conflict of Interest: The authors declare that the research was conducted in the absence of any commercial or financial relationships that could be construed as a potential conflict of interest.

Copyright (c) 2020 Elemosho, Irondi, Alamu, Ajani, Maziya-Dixon and Menkir. This is an open-access article distributed under the terms of the Creative Commons Attribution License (CC BY). The use, distribution or reproduction in other forums is permitted, provided the original author(s) and the copyright owner(s) are credited and that the original publication in this journal is cited, in accordance with accepted academic practice. No use, distribution or reproduction is permitted which does not comply with these terms. 